\title{
A Brief Review on the Possible Role of Houseflies and Cockroaches in the Mechanical Transmission of Coronavirus Disease 2019 (COVID-19)
}

\author{
Rouhullah Dehghani ${ }^{1}$ and Hamid Kassiri ${ }^{2, *}$ \\ ${ }^{1}$ Department of Environment Health, Social Determinants of Health Research Center, Kashan University of Medical Sciences, Kashan, Iran \\ ${ }^{2}$ Department of Medical Entomology, Faculty of Health, Ahvaz Jundishapur University of Medical Sciences, Ahvaz, Iran \\ "Corresponding author: Department of Medical Entomology, Faculty of Health, Ahvaz Jundishapur University of Medical Sciences, Ahvaz, Iran. Email: \\ hamid.kassiri@yahoo.com
}

Received 2020 March 18; Accepted 2020 March 24.

Keywords: Housefly, Cockroach, Mechanical Transmission, COVID-19

\section{Dear Editor,}

Emerging arboviral infections are defined as viral diseases that have lately emerged in a population, and are rapidly enhancing in a geographic range or abundance. Human ecology and behavior are two factors that play a key role in the emergence or re-emergence of these infections. For instance, the geographical extension of human populations, the growth of agriculture, and the invasion of habitats due to climate change or deforestation have simplified the appearance of some emerging or re-emerging arboviruses. There are at least 135 arboviruses that have been recognized to create human disease. Arboviral infections can range from asymptomatic to fatal disease. The clinical symptoms are commonly grouped as invasive neurological diseases, hemorrhagic fever, and systemic febrile illness (1).

Re-emerging and emerging pathogenic agents of zoonotic origin have become an important universal fear. The serious infectious diseases that are presumed to be of fear are graded as most important, comprising Middle East respiratory syndrome, Marburg, severe acute respiratory syndrome, Ebola virus disease, Lassa fever, Rift Valley fever, Crimean Congo hemorrhagic fever, and Nipah. The second group is graded as dangerous, comprising severe fever with thrombocytopenia syndrome, Zika, and chikungunya. The third group including avian influenza, tuberculosis, dengue HIV/AIDS, and malaria is considered dangerous. Some of these diseases are transmitted by insects and ticks $(2,3)$.

Coronaviruses can be transmitted through the fecaloral route, respiratory secretions, and direct contact by touching virus-contaminated surfaces, as well as the contact of hands (before washing) with the eyes, the nose, and the mouth. The vast majority of coronaviruses are moderately pathogenic, but they sometimes cause more severe conditions in humans, such as severe acute respiratory syndrome (SARS) and Middle East respiratory syndrome (MERS).

As one of the largest RNA viruses, coronaviruses have a genome size of 26 - $32 \mathrm{~kb}$. They are animal-originated enveloped viruses with single-stranded, positive-sense RNA; they belong to the family Coronaviridae, order Nidovirales, genus Betacoronavirus (3). Coronaviruses can cause respiratory disease in birds and mammals including humans. So far, seven types of human coronaviruses have been identified. Human coronaviruses $229 \mathrm{E}$ (HCoV-229E), NL63 (HCoVNL63), OC43 (HCoV-OC43), and HKU1 commonly infect people worldwide and cause respiratory infections in children and adults (3-5). Coronaviruses include MERS-CoV, SARS-CoV, and the newest one SARS-CoV-2 or CoV-2019 or COVID-19 virus or novel coronavirus-2019, which causes the corona virus disease. This disease began in Wuhan, China, in late 2019 with the high epidemic ability and human mortality. Now, it is a pandemic affecting more than 115 countries.

The COVID-19 virus is closely linked to a bat coronavirus. It has been suggested that the COVID-19 virus transmission and evolution path occurred from bats to scaly anteaters (pangolins) and then to humans. Currently, COVID-19 is thought to be transmitted via respiratory droplets, close contact, aerosols, and possibly the fecal-oral route, and patients can transmit the virus to others during the incubation period. Although there is one report of COVID-19 in patient's feces, its transmission via the oral-fecal route is still unknown. There is currently no antiviral treatment or vaccine for COVID-19 infections. Ac- 
cording to worldwide statistics, the mortality rate of the disease is 3.4\% (3, 6-8). Following the coronavirus epidemic crisis around the world, the coronavirus epidemic in Iran was formally confirmed on 18 February 2020. In Iran, the disease has a very high prevalence and a considerable mortality rate (3).

Arboviruses are a group of viruses that replicate in both their arthropod and vertebrate hosts. They are transmitted between vertebrates through the bite of bloodsucking arthropods. The vast majority of arboviruses belong to one of the five families Togaviridae, Flaviviridae, Bunyaviridae, Reoviridae, and Rhabdoviridae. There have been no reports of COVID-19 transmission by bloodsucking arthropods such as mosquitoes (9-13). However, insects such as cockroaches and houseflies, which are major mechanical vectors of pathogens, may be able to transmit the disease by contact with contaminated surfaces and even with the feces of infected individuals (14-16). The present study aimed to investigate the possibility of COVID-19 transmission by houseflies and cockroaches.

The coronavirus was first isolated in 1937. It was responsible for infectious bronchitis in birds and caused a lot of damage to the poultry industry. Then, in the 1960 s, scientists found evidence of human coronaviruses ( $\mathrm{HCoV}$ ) in patients infected with the common cold. Two human coronaviruses, OC43 and 229E, were responsible for a large proportion of the common cold. Other coronaviruses were then detected $(5,9)$. In late 2019 , a new coronavirus caused a pneumonia outbreak with symptoms such as fever, myalgia, and fatigue in Wuhan, China, which was followed by the disease spread throughout China and other countries and became a global health emergency. In February 2020, the World Health Organization named COVID-19 as a disease caused by the novel coronavirus-2019(nCoV-2019). The most important issue about COVID-19 is its transmission because it can be controlled if the transmission routes are known. Limited research is available on person-toperson $\mathrm{HCoV}$ transmission. However, researchers believe that these viruses are transmitted by respiratory secretions and through the mucosa. Respiratory coronaviruses are likely to spread via direct contact with contaminated discharge or large aerosol droplets in a fashion similar to that of rhinoviruses $(17,18)$. They can also be transmitted and spread through unprotected coughing and sneezing, direct contact of the hand with the noses, eyes, or mouths of patients, and contact with the surface of objects and equipment belonging to patients. Moreover, COVID-19 is transmitted via droplets during unprotected close contact between an infected person and a healthy person. Based on available evidence, airborne emission is not thought to be the main transmission route. Close contact of the healthy person with the infected individual may be the most im- portant mode of transmission. In addition, infected persons can contaminate the surfaces they touch, which may include a large number of household objects and home appliances (17). Previous studies showed that SARS coronavirus and other coronaviruses could survive on environmental surfaces and inanimate objects; however, the novel coronavirus 2019 has not been reported in the environment. According to the WHO, there is no certainty about the survival duration of the COVID-19 virus on surfaces, but this virus seems to act like other coronaviruses. Preliminary studies show that coronaviruses, including the COVID-19 virus, can remain on surfaces for several hours to several days. This may vary under different circumstances (e.g., surface type, temperature, and humidity of the environment) $(3,19,20)$.

Human-to-human transmission of the COVID-19 virus occurs mainly within families. Primary studies have shown that the secondary attack rate (the morbidity rate after infection of the first family member) within the families is 3\% - 10\%. Some other studies in Guangdong and Sichuan Provinces in China showed that 78\% - 85\% of transmissions occurred within families. According to these reports, residential houses have an important role in disease transmission. In a limited number of case reports, the live virus has been reported in the feces of patients (17). Wu et al. presented real-time RT-PCR findings of fecal and respiratory samples from cases with COVID-19 (SARSCOV-2) in China between January 16 - March 15, 2020. Respiratory samples remained positive for COVID-19 RNA for an average of 16.7 days, of the 41 (55\%) of 74 cases with fecal samples that were positive for COVID-19 RNA, and fecal samples remained positive for an average of 27.9 days after first symptom start (namely, for an average of $11 \cdot 2$ days longer than for respiratory samples). Specially, case 1 had positive fecal samples for 33 days continuously after the respiratory samples became negative, and case 4 examined positive for COVID -19 RNA in fecal sample for 47 days after first symptom start (21). However, the oral-fecal route does not appear to be responsible for the transmission of COVID-19. The role and importance of this route have not yet been determined, but feces can be considered a possible important source of COVID-19 transmission. Therefore, any organism in contact with or feeding on human feces may play a role in COVID-19 transmission. Therefore, the role of insects such as houseflies and cockroaches in the transmission of COVID-19 becomes important $(22,23)$. These insects have the potential to mechanically transmit pathogens such as viruses, bacteria, and parasites. They are capable of transmitting more than 100 pathogens through their legs, body hair, mouthparts, feces, and vomit. Houseflies and cockroaches eat a variety of substances including human and animal food waste, 
milk, sugar, rotten fruits, sputum, nasal secretions, various wastes, fresh and dried blood, decaying corpses, stool, etc. Given that these insects eat contaminated materials, return them, and defecate on food materials, they are among the most important insects that can mechanically carry bacteria, viruses, worm eggs, and protozoan cysts. Flies and cockroaches play a role in the transmission of agents that cause diseases such as tuberculosis, leprosy, diarrhea, dysentery, cholera, typhoid, trachoma, conjunctivitis, polio, and hepatitis A. They are also vectors of rotaviruses, coronaviruses, some fungi (such as those in the genera Trichophyton and Candida) and eggs of parasitic worms and protozoan cysts. Flies and cockroaches are restless, active insects with strong visual and olfactory powers, and are constantly moving between food, feces, objects, and humans (14-16, 24-29). In a study to investigate SARS coronavirus carried by cockroaches, 15 cockroach surface swabs were tested by nested RT-PCR and only one uncertain positive result of the cockroach surface was found by nested RT-PCR (27).

There have been reports of COVID-19 transmission in prisons, hospitals, and other places where people live together for a long time from various Chinese provinces. The proximity and close contact of people in such places and the potential for environmental contamination are important factors that can enhance transmission (17). Coronaviruses are mostly reported in temperate climates, and coronavirus-induced respiratory infections occur mainly in winter although smaller peaks can be sometimes observed in autumn or spring. Infections can occur at any time of the year (30-32). A seven-year study of children hospitalized in Guangzhou, China, showed the seasonality of the disease in the subtropical region. There was a clear seasonal pattern in the presentation of $\mathrm{HCoV}$ patients over seven years. The outbreak occurred almost every season of the year but the overall prevalence of $\mathrm{HCoV}$ was mainly observed in spring and autumn (33). Preventive measures are similar to those of rhinovirus infections, which include hand washing and careful disposal of nasal secretion-contaminated materials. The use of surface disinfectants is also an important issue in infection control because coronaviruses have survived for one to several days on dry surfaces such as stainless steel, plastics, or fabrics (34).

Dealing with the COVID-19 virus and preventing its rapid and dangerous spread is a global challenge. Therefore, the fight against this disease requires universal management. However, given the potential variability of the disease according to the types of climate and other environmental factors, its prevention and control should be planned regionally. As the disease is common in temperate regions in cold seasons, the prevention and control meth- ods should be tailored to the environmental and seasonal conditions and the needs of each region. Using the right vaccine is definitely the best method of disease prevention, but environmental control methods must be emphasized until an effective vaccine is made (3). In this regard, it is important to eliminate possible mechanical vectors such as cockroaches and flies in public places and residential homes. Control methods of houseflies and cockroaches include improved environmental sanitation such as placing waste in closed bags and waste bins with lids, sanitary landfill sites, hygienic toilets, proper sewage disposal systems, and prevention of livestock manure accumulation in the vicinity of residential areas. Installing stainless or plastic screens on doors, windows, and ventilators, covering food containers, and using poisoned baits, light traps, and sticky traps are some physical and mechanical control methods of these insects. Chemical control using insecticides should be carried out after consultation with specialists because of their potential risks. In addition, medicinal plants such as lavender and eucalyptus are also very effective in repelling houseflies. Biological control and application of parasitoids is a safe and environmentally friendly way of controlling these insects. Decaying materials, landfills, the areas around livestock and poultry farms, animal carcasses, garbage cans, and so on can attract houseflies and cockroaches to their lay eggs on them (14-16, 23-25).

\section{Footnotes}

Authors' Contribution: Rouhullah Dehghani and Hamid Kassiri developed the original idea and the protocol, abstracted and analyzed data, and wrote the manuscript.

Conflict of Interests: No conflict of interest is reported. Funding/Support: None is declared by the authors.

\section{References}

1. Mayer SV, Tesh RB, Vasilakis N. The emergence of arthropod-borne viral diseases: A global prospective on dengue, chikungunya and zika fevers.Acta Trop. 2017;166:155-63. doi:10.1016/j.actatropica.2016.11.020. [PubMed: 27876643]. [PubMed Central: PMC5203945].

2. Morens DM, Fauci AS. Emerging infectious diseases: Threats to human health and global stability. PLoS Pathog. 2013;9(7). e1003467. doi: 10.1371/journal.ppat.1003467. [PubMed: 23853589]. [PubMed Central: PMC3701702].

3. Farnoosh G, Alishiri G, Hosseini Zijoud SR, Dorostkar R, Jalali Farahani A. Understanding the 2019-novel coronavirus (2019-nCoV) and coronavirus disease (COVID-19) based on available evidence-a narrative review. J Mil Med. 2020;22(1):1-11.

4. National center for immunization and respiratory diseases (NCIRD). Division of viral diseases. Human coronavirus types. 2020, [cited 2020 Feb 15]. Available from: https://www.cdc.gov/coronavirus/types. html. 
5. Gorbalenya AE, Baker SC, Baric RS, de Groot RJ, Drosten C, Gulyaeva AA, et al. Severe acute respiratory syndrome-related coronavirus: The species and its viruses - a statement of the coronavirus study group. BioRxiv. 2020;1-15. doi: 10.1101/2020.02.07.937862.

6. Wu F, Zhao S, Yu B, Chen YM, Wang W, Song ZG, et al. A new coronavirus associated with human respiratory disease in China. Nature. 2020;579(7798):265-9. doi: 10.1038/s41586-020-2008-3. [PubMed: 32015508]. [PubMed Central: PMC7094943].

7. Zhou P, Yang XL, Wang XG, Hu B, Zhang L, Zhang W, et al. A pneumonia outbreak associated with a new coronavirus of probable bat origin. Nature. 2020;579(7798):270-3. doi: 10.1038/s41586-020-2012-7. [PubMed: 32015507]. [PubMed Central: PMC7095418].

8. Carlos WG, Dela Cruz CS, Cao B, Pasnick S, Jamil S. Novel Wuhan (2019$\mathrm{nCoV}$ ) coronavirus. Am J Respir Crit Care Med. 2020;201(4):P7-8. doi: 10.1164/rccm.2014P7. [PubMed: 32004066].

9. Sanchez-Vargas I, Travanty EA, Keene KM, Franz AW, Beaty BJ, Blair CD, et al. RNA interference, arthropod-borne viruses, and mosquitoes. Virus Res. 2004;102(1):65-74. doi: 10.1016/j.virusres.2004.01.017. [PubMed: 15068882].

10. Adler PH, Wills W. Legacy of death the history of arthropod-borne human diseases in South Carolina. Am Entomol. 2003;49(4):216-28. doi: 10.1093/ae/49.4.216.

11. Weaver SC. Urbanization and geographic expansion of zoonotic arboviral diseases: Mechanisms and potential strategies for prevention. Trends Microbiol. 2013;21(8):360-3. doi: 10.1016/j.tim.2013.03.003. [PubMed: 23910545]. [PubMed Central: PMC5193003].

12. Centers for disease control and prevention (CDC). Coronavirus disease 2019 (COVID-19), how it spreads. 2020, [cited 2020 Mar 20]. Available from: https://www.cdc.gov/coronavirus/2019-ncov/prepare/ transmission.html.

13. Can mosquitoes transmit the coronavirus? 2020. Available from: www. mosquito.org.

14. Kassiri H, Akbarzadeh $\mathrm{K}$, Ghaderi A. Isolation of pathogenic bacteria on the house Fly, Musca domestica L. (Diptera: Muscidae), body surface in Ahwaz Hospitals, Southwestern Iran. Asian Pac J Trop Biomed. 2012;2(2):S1116-9. doi: 10.1016/s2221-1691(12)60370-0.

15. Vazirianzadeh B, Mahdinezhad M, Dehghani R. Identification of bacteria which possible transmitted by Polyphaga aegyptica (Blattodea: Blattidae) in the region of Ahvaz, SW Iran. Jundishapur J Microbiol. 2009;2(1):36-40.

16. Vazirianzadeh B, Dehghani R, Mehdinejad M, Sharififard M, Nasirabadi $\mathrm{N}$. The first report of drug resistant bacteria isolated from the brown-banded cockroach, Supella longipalpa, in Ahvaz, South-Western Iran. J Arthropod Borne Dis. 2014;8(1):53-9. [PubMed: 25629065]. [PubMed Central: PMC4289511].

17. Report of the WHO-China joint mission on coronavirus disease 2019 (COVID-19). 2020, [cited 2020 Feb 24]. Available from: https://www.who.int/docs/default-source/coronaviruse/whochina-joint-mission-on-covid-19-final-report.pdf.

18. Reed SE. The behaviour of recent isolates of human respiratory coronavirus in vitro and in volunteers: evidence of heterogeneity among 229E-related strains. J Med Virol. 1984;13(2):179-92. doi: 10.1002/jmv.1890130208. [PubMed: 6319590].

19. Casanova LM, Jeon S, Rutala WA, Weber DJ, Sobsey MD. Effects of air temperature and relative humidity on coronavirus survival on surfaces. Appl Environ Microbiol. 2010;76(9):2712-7. doi: 10.1128/AEM.0229109. [PubMed: 20228108]. [PubMed Central: PMC2863430].

20. Kampf G, Todt D, Pfaender S, Steinmann E. Persistence of coronaviruses on inanimate surfaces and their inactivation with biocidal agents. J Hosp Infect. 2020;104(3):246-51. doi: 10.1016/j.jhin.2020.01.022. [PubMed:32035997].
21. Wu Y, Guo C, Tang L, Hong Z, Zhou J, Dong X, et al. Prolonged presence of SARS-CoV-2 viral RNA in faecal samples. Lancet Gastroenterol Hepatol. 2020. doi:10.1016/S2468-1253(20)30083-2. [PubMed: 32199469].

22. Parry J. WHO queries culling of civet cats. BMJ. 2004;328(7432):128. doi: 10.1136/bmj.328.7432.128-b. [PubMed: 14726333]. [PubMed Central: PMC1150312].

23. Nasirian H. Infestation of cockroaches (Insecta: Blattaria) in the human dwelling environments: A systematic review and meta-analysis. Acta Trop. 2017;167:86-98. doi: 10.1016/j.actatropica.2016.12.019. [PubMed: 28012906].

24. Kassiri H, Zarrin M, Veys-Behbahani R, Faramarzi S, Kasiri A. Isolation and identification of pathogenic filamentous fungi and yeasts from adult house fly (Diptera: Muscidae) captured from the Hospital Environments in Ahvaz City, Southwestern Iran. J Med Entomol. 2015;52(6):1351-6. doi:10.1093/jme/tjv140. [PubMed: 26405077].

25. Sharififard M, Safdari F, Siahpoush A, Kassiri H. Evaluation of some plant essential oils against the brown-banded cockroach, Supella longipalpa (Blattaria: Ectobiidae): A mechanical vector of human pathogens. J Arthropod Borne Dis. 2016;10(4):528-37. [PubMed: 28032105]. [PubMed Central: PMC5186743].

26. Khamesipour F, Lankarani KB, Honarvar B, Kwenti TE. A systematic review of human pathogens carried by the housefly (Musca domestica L.). BMC Public Health. 2018;18(1):1049. doi: 10.1186/s12889-018-59343. [PubMed: 30134910]. [PubMed Central: PMC6104014].

27. Duan JH, Wu J, Lin LF. Preliminary report on SARS coronavirus detection from vector rat and cockroach by RT-PCR. Chin J Vector Biol Control. 2003;14(5):332-4

28. Yi JR, Lin LF, Duan JH, Wu J, Pei FQ, Lu WC, et al. Analysis on murinelike animals carrying SARS coronavirus in the hygienic units related to SARS. Chin J Vector Biol Control. 2004;15(1):7-9.

29. Mayr A. [Spread of infectious agents through refuse by domestic, community and field parasites with special reference to human health]. Zentralbl bakteriol mikrobiol Hyg B. 1983;178(1-2):53-60. Germany. [PubMed: 6649998].

30. McIntosh K, Kapikian AZ, Turner HC, Hartley JW, Parrott RH, Chanock RM. Seroepidemiologic studies of coronavirus infection in adults and children. Am J Epidemiol. 1970;91(6):585-92. doi: 10.1093/oxfordjournals.aje.a121171. [PubMed: 4315625].

31. Vabret A, Dina J, Gouarin S, Petitjean J, Tripey V, Brouard J, et al Human (non-severe acute respiratory syndrome) coronavirus infections in hospitalised children in France. J Paediatr Child Health. 2008;44(4):176-81. doi: 10.1111/j.1440-1754.2007.01246.x. [PubMed: 17999671].

32. Gaunt ER, Hardie A, Claas EC, Simmonds P, Templeton KE. Epidemiology and clinical presentations of the four human coronaviruses 229E, HKU1, NL63, and OC43 detected over 3 years using a novel multiplex real-time PCR method. J Clin Microbiol. 2010;48(8):29407. doi: 10.1128/JCM.00636-10. [PubMed: 20554810]. [PubMed Central: PMC2916580].

33. Zeng ZQ, Chen DH, Tan WP, Qiu SY, Xu D, Liang HX, et al. Epidemiology and clinical characteristics of human coronaviruses OC43, 229E, NL63, and HKU1: A study of hospitalized children with acute respiratory tract infection in Guangzhou, China. Eur J Clin Microbiol Infect Dis 2018;37(2):363-9. doi: 10.1007/s10096-017-3144-z. [PubMed: 29214503] [PubMed Central: PMC5780525].

34. Otter JA, Donskey C, Yezli S, Douthwaite S, Goldenberg SD, Weber DJ Transmission of SARS and MERS coronaviruses and influenza virus in healthcare settings: the possible role of dry surface contamination. J Hosp Infect. 2016;92(3):235-50. doi: 10.1016/j.jhin.2015.08.027. [PubMed: 26597631]. 